\title{
N-Fenilbenzamidas como Inibidores da Enzima Oxidase Alternativa (AOX) de Moniliophthora perniciosa
}

\author{
Maria Luiza L. Vieira*, Dra. Silvana A. Rocco, Mario R. O. Barsottini, Dr. Gonçalo A. G. Pereira, Bárbara Aliende \\ Pires, Dr. Mauricio L. Sforça, Paulo C. S. Costa, Dr. Marcelo Falsarella Carazzolle, Alessandro Coradini
}

\section{Resumo}

O cacaueiro (Theobroma cacao) é muito atingido pela doença vassoura-de-bruxa, causada pelo fungo Moniliophthora perniciosa. A doença é um dos maiores problemas fitopatológicos do Brasil. Para o combate tem sido estudada a inibição da enzima Oxidase Alternativa (AOX), uma proteína transmembrana parte da cadeia respiratória do fungo. Sua função é permitir que a respiração do fungo continue com a via principal bloqueada. O objetivo dessa pesquisa foi projetar e sintetizar derivados das $\mathrm{N}$-fenilbenzamidas, que mostraram atividade inibitória contra a enzima em testes preliminares com três compostos, a partir das suas estruturas, planejou-se uma bilbioteca com 146 derivados. Para a sua obtenção utilizou-se uma rota sintética baseada na reação clássica de Schöttem-Baumann. Após a caracterização físico-química das moléculas, utilizou-se para os testes de atividade a levedura Pichia pastoris que foi um bom modelo de avaliação biológica. Assim, foram triados 42 compostos com potencial de inibição da atividade da AOX.

\section{Palavras-chave:}

N-fenilbenzamidas, Oxidase Alternativa (AOX), Síntese Orgânica.

\section{Introdução}

A doença vassoura-de-bruxa em Theobroma cacao, causada pelo fungo Moniliophthora perniciosa, é um dos maiores problemas fitopatológicos no Brasil, gerando grandes prejuízos, seu combate teria um importante impacto econômico na agricultura nacional ${ }^{1}$.

Um promissor caminho é o desenvolvimento de moléculas para a inibição da enzima Oxidase Alternativa (AOX), uma proteína transmembrana que serve de rota respiratória alternativa no caso de bloqueio da via principal.

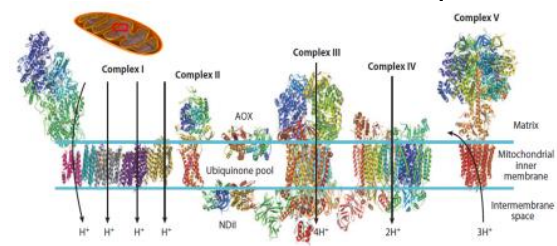

Figura 1: Cadeia respiratória do M. Perniciosa²

Estudos preliminares mostraram que derivados de $\mathrm{N}$ fenilbenzamidas seriam muito promissores na inibição da AOX. Este projeto tem por objetivo a síntese de uma biblioteca e a caracterização de $N$-fenilbenzamidas, de forma a completar a biblioteca de compostos com todos os dados. Também foram feitos testes sobre a atividade biológica dessas moléculas e comprovou-se sua atividade.

\section{Resultados e Discussão}

A AOX pode ser inibida por diversos compostos, como o ácido hidroxâmico (SHAM), porém eles não são adequados como fungicidas. Desenvolveu-se uma rota sintética para derivados de $N$-fenilbenzamida, inicialmente baseada na reação de Schöttem-Baumann ${ }^{3}$, uma reação clássica empregada para a síntese de amidas a partir de aminas com haletos de acila e com bases aquosas ${ }^{3}$. Foram feitas várias combinações de substituintes pelo padrão da figura 2.

A série de moléculas foi nomeada como $7 \mathrm{~J}-\mathrm{n}$ e conta com 146 moléculas sintetizadas com pureza adequada e rendimento médio de $70 \%$. A caraterização foi feita por RMN, medidas de ponto de fusão e análises de HPLC/UV. As condições foram alteradas para se adequar aos reagentes, foi utilizado diclorometano e 1 equivalente mol de cloreto ácido e amina e $\mathrm{HCl}$ 0,5M. 